\title{
Setores orgânico e inorgânico na formação social brasileira em Caio Prado Jr.
}

Organic and inorganic concepts in the sociohistorical formation of Brazil according to Caio Prado Jr

\author{
Evelyne Medeiros Pereira* \\ Milena Fernandes Barroso**
}

\begin{abstract}
Resumo - A realidade brasileira possui como marca na sua formação sócio-histórica a constante dialética entre mudança e permanência, renovação e ruptura, que se revela particularmente na atual conjuntura do país. Tal marca compõe a dinâmica do desenvolvimento capitalista, aprofundando-se nos países dependentes. Assim, buscamos dialogar com alguns importantes autores que ousaram interpretar o Brasil sob a ótica das contradições do complexo e histórico movimento entre o universal e o singular. Para tanto, priorizamos a obra Formação do Brasil contemporâneo (1942), de Caio Prado Jr., com especial atenção à análise feita pelo autor sobre o que se configurou como "orgẩnico" e "inorgânico" na constituição da economia e das classes sociais no país.
\end{abstract}

Palavras-chave: orgânico e inorgânico; classes sociais; formação sócio-histórica e econômica brasileira.

\begin{abstract}
Brazilian reality has a permanent dialectic as a mark in its sociohistorical formation, between change and permanence, renewal and rupture, that shows itself particularly well in the country's current conjuncture. Such a mark represents the dynamics of capitalist development, running deeper in developing countries. Thus, we seek to establish a dialogue with some important authors who interpreted Brazil boldly from the perspective of contradictions inherent to the complex and historical movement between universal and singular. Therefore, we prioritize the Caio Prado Jr.'s work Formation of Contemporary Brazil (1942), giving special attention to his analysis on what constitutes the "organic" and the "inorganic" in the constitution of economy and social classes in the country.

Keywords: organic and inorganic concepts; social classes; sociohistorical and economical formation of Brazil.
\end{abstract}

\footnotetext{
*Assistente Social. Doutoranda em Serviço Social na Universidade Federal do Rio de Janeiro (UFRJ). Docente do Curso de Serviço Social do Instituto Federal de Educação, Ciência e Tecnologia do Ceará (IFCE), campus Iguatu. Correspondência: Rua do Catete, 123. Casa 14. Bairro Catete. Rio de Janeiro - RJ. CEP: 22220-000. Email: <evelyne. mp2913@gmail.com>.

** Assistente Social. Doutoranda em Serviço Social na Universidade do Estado do Rio de Janeiro (UERJ). Bolsista da Fundação de Amparo à Pesquisa do Estado do Amazonas (FAPEAM). Docente do Curso de Serviço Social da Universidade Federal do Amazonas (UFAM), campus de Parintins. Correspondência: Rua Silveira Martins, 40/307. Bairro Catete. Rio de Janeiro - RJ. CEP. 22221-000. Email: <mibarroso@yahoo.com.br>.
} 


\section{Introdução}

Caio Prado foi um dos primeiros autores brasileiros a sistematizar o pensamento crítico sobre o Brasil a partir da análise do desenvolvimento do modo de produção capitalista. Este desenvolvimento promoveu, desde a colonização, a inserção particular do país na divisão internacional do trabalho, mesmo que de forma germinal.

É, pois, em busca do "sentido da colonização" brasileira que o autor encontra o caminho para grande parte de sua reflexão e continua a nos provocar até o tempo presente. Isto porque muitos dos aspectos históricos apresentados por ele persistem, com outros contornos e novas dimensões, como uma expressão do Brasil contemporâneo. Conhecer tais aspectos com maior profundidade torna-se central para analisar a particularidade das classes sociais, com um evidente recorte étnico-racial, regional e de gênero/sexo, sob uma determinada formação social que se constitui como economia dependente, com intensas e profundas contradições sociais, conformando o padrão capitalista de acumulação.

Tal formação é também atravessada por processos políticos autoritários, de conservação da ordem e de democracia restrita (FERNANDES, 2006). Sobre isso, Prado Jr. (2012) chama a atenção para o Período Imperial, de 1837 a 1849, como sendo aquele mais reacionário de nossa história, em que os movimentos populares são rigidamente reprimidos, a violência do Estado se torna prática comum e a insegurança se faz sentir na vida de grande parte da população. A partir de então, diversos eventos marcarão a presença do autoritarismo na história política republicana do Brasil, sob o respaldo de leis e instituições dominantes, em suma, do Estado, o que faz do país não uma exceção, tendo em vista que essa, dentre tantas, é uma marca comum nas relações sociais capitalistas. Porém, terá uma maior tônica na realidade priorizada por nós. ${ }^{1}$

Nessa direção, conquistas históricas no âmbito dos direitos sociais às classes populares são continuamente atacadas por setores conservadores, representantes da "burguesia associada" (IANNI, 2004), (re)pondo temas na opinião pública que nos fazem inevitavelmente lembrar o quanto ainda está viva a nossa "herança colonial". Um exemplo disso foi a reação conservadora, civil e militar, frente à proposta em prol das reformas sociais de base, anunciadas nos anos 1960, pelo então presidente João Goulart, demonstrando o quanto os setores dominantes e hegemônicos no país podem ser reacionários. No período mais recente, é possível identificar

\footnotetext{
${ }^{1}$ Desde a fundação da República, podem ser contabilizados 76 anos de períodos considerados "autoritários", sejam eles ditatoriais ou com pouca liberdade política, e apenas 50 anos de períodos considerados "democráticos", sendo contabilizadas aí eleições diretas para todas as esferas e presidentes diretamente eleitos pelo sufrágio popular.
} 


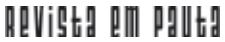

\} SETORES ORGÂNICO E INORGÂNICO NA FORMAÇÃO SOCIAL BRASILEIRA - PEREIRA, E. M.; BARROSO, M. F. \}

DOI: $10.12957 /$ REP.2016.27844

uma ameaça ainda maior à tão parca democracia brasileira com o fortalecimento de concepções fundamentalistas e fascistas, forjadas de um "novo verde-amarelismo", contrárias aos ganhos, mesmo que mínimos, dos segmentos mais subalternizados da sociedade.

Tais concepções ganham expressividade, por exemplo, no Congresso Nacional, através de pautas travestidas de "combate à corrupção" ou de "enfrentamento à crise econômica e política", tais como: o incentivo às terceirizações; a flexibilização nas relações de trabalho; mais privatização do setor público; o retrocesso na área dos direitos sociais (especialmente saúde e educação), sexuais e reprodutivos; as restrições nos processos de demarcação de terras indígenas e quilombolas; a criminalização aos movimentos sociais, isto para citarmos alguns. Ainda, contrariando a ideia do Brasil como um país da "democracia racial", apresentam-se, nas instâncias oficiais de poder e fora dela, manifestações de homofobia, racismo, sexismo e xenofobia, que reforçam o estigma ao pobre e às políticas sociais. Isso sem falar dos anseios pró-ditadura, que demostram o termômetro da atual correlação de forças sociais no Brasil e ratificam a tendência autoritária da sociedade brasileira, tal como analisou Caio Prado Jr. (2012).

A história do Brasil sinaliza, portanto, a permanente dialética entre mudanças e continuidades, possuindo este segundo polo um maior peso. Contudo, é importante lembrar que a realidade brasileira não é uma excepcionalidade, mas partícipe da dinâmica de um desenvolvimento desigual e combinado, inerente ao modo de produção capitalista, aprofundando-se nos países dependentes e/ou periféricos, em um cenário de mundialização e crise estrutural do capital.

Cabe ressaltar que a tese do desenvolvimento desigual e combinado (que aparece indiretamente na obra pradiana ao considerar o passado também como presente, através das heranças do escravismo, da questão indígena e agrária) trata-se de uma das maiores contribuições de Trotsky (1977) à teoria marxista. Refere-se à ocorrência concomitante de aspectos considerados "avançados" e "atrasados" no modo de produção capitalista. Essa tese também pode ser estudada de forma articulada com a concepção desenvolvida por Lenin (1982) de formação econômico-social, mediação fundamental entre as categorias de "modo de produção" e "desenvolvimento desigual e combinado", necessária para o entendimento das particularidades existentes em determinadas formações sociais, a exemplo da própria Rússia ou mesmo de países dependentes como o Brasil.

Isso nos leva a entender que, do ponto de vista da totalidade social, existem tendências contemporâneas que, de forma particular, trazem consequências para a realidade do país, (re)criando desigualdades através da articulação entre a acumulação capitalista, o Estado e a burguesia local.

Diante desse cenário e do desafio que ele põe àqueles que buscam analisá-lo sob uma perspectiva histórico-crítica, revisitar obras de importantes pensadores que, por sua atualidade, são clássicos, foi o caminho que 
tomamos. Assim, priorizamos, neste artigo, traçar um diálogo breve e introdutório com Caio Prado Jr., já que sua obra é reconhecida por apanhar a história em seu movimento, "como um caleidoscópio de ciclos", diversidades e desigualdades sociais, regionais, econômicas, políticas e culturais.

Para tanto, nos apoiaremos, em especial, na obra Formação do Brasil contemporâneo, de 1942, que, de antemão, nos diz ser o Brasil uma nação que, assim como outras, possui um "sentido" em sua formação enraizado por aquele caráter inicial da colonização, peça-chave da explicação dos elementos fundamentais. Ao tentar encontrar o sentido da colonização brasileira no contexto de expansão capitalista, Prado Jr. nos aponta pistas importantes para pensarmos o país a partir do movimento da história, de rupturas e permanências, de avanços e retrocessos, em que o velho se reatualiza no novo e este também se faz velho. Nesse caminho, o autor alude aos aspectos que configuram os setores orgânico e inorgânico na sociedade brasileira como mediações para entender a configuração da economia e das classes sociais, o que será o fio condutor do texto que aqui se apresenta.

Certamente não seria possível contemplar, neste artigo, a grandiosidade do conjunto da obra de Caio Prado Jr., que, já na década de 1930, mediante a dificuldade encontrada no acesso a dados, estatísticas e demais edições, inclusive de clássicos da tradição marxista, conseguiu construir uma análise profunda, que foge do dogmatismo, é inovadora e, por que não dizer, contemporânea da realidade brasileira, abrindo caminho para outras tantas importantes contribuições. Por outro lado, nota-se também que Caio Prado foi um homem do seu tempo, sofrendo influências, mesmo que com resistências, de interpretações e perspectivas vigentes em sua época, por exemplo, nas Ciências Sociais da primeira metade do século XX, perceptível no trato de alguns temas como o da questão racial. Porém, esse aspecto não reduz a relevância de sua obra e a necessidade de atualizá-la a partir do diálogo com outros pensadores, clássicos e contemporâneos, e com a própria realidade brasileira.

\section{A construção da vida material sob a herança do Brasil colonial}

A formação social do Brasil é atrelada substancialmente ao caráter agrário, às relações políticas conservadoras e autoritárias e à dependência econômica. A agricultura foi a base do avanço do capitalismo no país desde o período da colonização, viabilizando historicamente a acumulação de capital. Sobre isso, conforme já explicita lamamoto (2007, p. 136), a questão agrária no Brasil, em interface com a questão social, é decisiva para a compreensão das formas históricas assumidas pelo Estado "mediante os interesses de classes vinculados à propriedade territorial na composição política do poder interferindo nas grandes transformações operadas na vida da nação". 


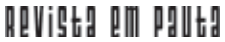

\} SETORES ORGÂNICO E INORGÂNICO NA FORMAÇÃO SOCIAL BRASILEIRA - PEREIRA, E. M.; BARROSO, M. F. \}

DOI: $10.12957 /$ REP.2016.27844

Tais condições revelam o caráter (híbrido) do padrão de acumulação no país, tendo como principal expressão o pauperismo no campo e nas cidades. Nesse contexto, as classes sociais vão se conformando sob um conjunto de fatores, dentre estes, um acentuado cunho colonial característico de um passado longínquo, mas que ainda nos cerca de todos os lados (PRADO JR., 2008).

Para nosso intérprete, o processo de colonização particularizou o caráter do capitalismo no país, revelando como o moderno se articula permanentemente com o arcaico, fundado no período colonial, mediante dinâmica realizada por meio de mecanismos ainda não essencialmente capitalistas, a exemplo do próprio trabalho escravo, não tendo como "meio ambiente original" o feudalismo. Dessa forma, para o autor, o Brasil contemporâneo define-se como
o passado colonial que se balanceia e encerra com o século XVIII, mais as transformações que se sucederam no decorrer do centênio anterior a este e no atual. Naquele passado se constituíram os funda- mentos da nacionalidade: povoou-se um território semideserto, organi- zou-se nele uma vida humana que diverge tanto daquela que havia aqui, dos indígenas e suas nações, como também, embora em menor escala, da dos portugueses que empreenderam a ocupação do terri- tório. Criou-se no plano das realizações humanas algo de novo [...] uma população bem diferenciada e caracterizada, até etnicamente, e habitando um determinado território; uma estrutura material par- ticular, constituída na base de elementos próprios; uma organização social definida por relações específicas; finalmente, até uma cons- ciência, mais precisamente, uma certa 'atitude' mental coletiva parti- cular. (PRADO JR., 2008, p. 10).

Assim, a nossa colonização configurou-se como expressão de uma "nova ordem que é a do mundo moderno", derivada do desenvolvimento do comércio continental europeu. Daí nasce o Brasil, como uma "colônia de exploração", ou seja, uma vasta empresa comercial tendo como base três principais pilares: a grande propriedade (plantation), a monocultura e o trabalho escravo. Foi em meio à produção em larga escala, mediante grandes unidades produtoras e concentração de uma grande quantidade de trabalhadores, junto a uma minoria de proprietários intermediados por relações patriarcais, que a modernidade nasceu no Brasil. Tais aspectos conformaram o que Prado Jr. (2008) denominou de "caráter orgânico" da sociedade, nossa "essência", tema no qual nos deteremos mais adiante.

Dialogando com essa concepção, Oliveira (2013, p. 33) reforça o seguinte: "as economias pré-industriais da América Latina foram criadas pela expansão do capitalismo mundial, como uma reserva de acumulação primitiva do sistema global". Isto deslegitima a acepção daqueles que acreditam na existência de um "subdesenvolvimento" que necessita ser superado por intermédio do próprio desenvolvimento capitalista, quando 


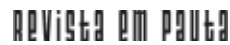

\} SETORES ORGÂNICO E INORGÂNICO NA FORMAÇÃO SOCIAL BRASILEIRA - PEREIRA, E. M.; BARROSO, M. F. \}

DOI: $10.12957 /$ REP.2016.27844

este, na verdade, aprofunda a dependência. ${ }^{2}$ Trata-se, portanto, de uma via "não clássica" em que a transição para o capitalismo ocorre sem profundas alterações na estrutura social e econômica, especialmente agrária.

Esse lastro é central na conformação do capitalismo brasileiro e de suas classes fundamentais. Estas, formadas por "trabalhadores dependentes, sejam escravos ou assalariados, ou sem formas intermediárias de trabalho, representa o sistema de organização agrária" (PRADO JR., 2008, p. 118).

Daí, desde a colônia, desencadeia-se um processo que poderíamos associar, nos termos de Marx (2006), à acumulação primitiva, marcada por um sistema de organização do trabalho (com base na sua grande exploração) e concentração extrema de propriedade fundiária (expropriada dos povos nativos) e riqueza em geral. Muito embora não tenha sido realizado pelas chamadas classes fundamentais do modo de produção capitalista - burguesia e proletariado -, isso abre, nas palavras de Prado Jr. (2008, p. 279), "um vácuo imenso entre os extremos da escala social: os senhores e os escravos; a pequena minoria dos primeiros e a multidão dos últimos [...] os primeiros serão os dirigentes da colonização nos seus vários setores; os outros, a massa trabalhadora".

Para nosso intérprete, outro sentido da colônia que se perpetuou no Brasil contemporâneo refere-se à organização da produção para fora, na subordinação ao mercado externo. Nos termos do autor, a nossa economia se subordina e "se organizará e funcionará para produzir e exportar aqueles gêneros (açúcar, algodão, ouro). Será subsidiário e destinado unicamente a amparar e tornar possível a realização daquele fim essencial" (PRADO JR., 2011, p. 123). É evidente a centralidade do processo de colonização para o desencadeamento da acumulação originária de capital nos países centrais. A economia colonial, para atender a esse fim, tinha como base a produção de gêneros agrícolas a partir da agricultura, como também as demais atividades vinculadas à mineração e ao extrativismo - este sob condições bem específicas.

$\mathrm{Na}$ agricultura, a característica central era a grande unidade produtora. Para Caio Prado (2011, p. 124), "é neste sistema de organização do trabalho e da propriedade que se origina a concentração extrema de riqueza que caracteriza a economia colonial". Esta teve como o mais importante elemento o trabalho escravo, aspecto central, orgânico, da sociedade brasileira na colonização. Ainda conforme o autor,

Nas circunstâncias gerais [...] que presidem à colonização brasileira [...], as relações de produção e trabalho se estabelecem necessa-

\footnotetext{
${ }^{2}$ Na América Latina, este debate foi germinado nas décadas de 1960 e 1970 por intelectuais da conhecida Teoria Marxista da Dependência (TMD), que passam a defender a tese de que o desenvolvimento econômico não se dá por etapas e que a superação da dependência brasileira não passaria pelo desenvolvimento da industrialização, mas implicaria a ruptura com o próprio capitalismo.
} 
riamente na base da separação entre a propriedade dos meios de produção, de um lado, e de outro, o fornecimento da força de trabalho. Trata-se naquele empreendimento, centralmente, de um negócio, de uma empresa comercial [...]. (PRADO JR., 1972, p. 40).

Vale ressaltar que no Brasil, diferentemente do que ocorreu em outros territórios onde a grande propriedade se realizava pelas formas de arrendamento e aforamento, a vasta extensão de terra se articula à exploração em larga escala - aspecto comum ao modo de produção capitalista, centralmente ao processo de cooperação e divisão social do trabalho, tendo como base a propriedade privada (MARX, 2006). Sobre isso, Prado Jr. apresenta a agricultura nos trópicos como uma das características de cultivo e o mais antigo dos métodos modernos de agricultura em larga escala especializada. Aqui também encontramos elementos de atualidade na obra pradiana. Não é estranho, por exemplo, que, na última década, analistas apontem para uma tendência ao fortalecimento de uma economia baseada em exportações via commodities que representaria um retorno ao passado na política econômica do Brasil (GONÇALVES, 2010). Para Ricupero (2007, n.p.), "não é difícil perceber, em tempos da chamada globalização, a atualidade dessa perspectiva. Talvez se possa até sugerir que nosso moderno agrobusiness não é muito diferente da grande exploração".

Cabe ressaltar o papel do agronegócio e dos grandes projetos subsidiados predominantemente nos anos 2000 pelo Banco Nacional de Desenvolvimento Econômico e Social (BNDES), que, no período mais recente, disponibilizou por volta de um terço do total dos recursos "para somente dez grandes grupos econômicos privados em processo de concentração e fusão". Ao considerar as empresas estatais, "chega-se ao resultado de quase dois terços do total dos recursos desembolsados pelo banco público para apenas doze grandes corporações nacionais privadas e estatais" (POCHMANN, 2013, p. 152). Enquanto isso, a reforma agrária continua sem avançO.

Já no âmbito da mineração, houve, para Prado Jr. (2011), uma organização semelhante à da agricultura, fundada na exploração em larga escala, em grandes unidades trabalhadas por escravos. Porém, diferentemente da agricultura, não constitui uma forma orgânica e estável, mas foi gradualmente extinta, resultado da decomposição do regime econômico e social das minas.

O extrativismo, por sua vez, considerado por nosso autor como o terceiro setor das grandes atividades fundamentais da economia brasileira, tem na geografia uma característica central: ocorreu quase exclusivamente na Região Amazônica. Sua organização se diferencia da agricultura e da mineração pois não teve por base a grande propriedade territorial: os trabalhadores tinham a liberdade de se dirigir para onde lhes convinha na floresta, propriedade comum à época. 
Trata-se em suma de uma exploração primitiva e rudimentar, um primeiro esboço de organização econômica que não será ultrapassada até o fim da era colonial. Mas afora isso, a extração não se distingue, na organização do seu trabalho e estruturação econômica, dos demais setores da atividade colonial. Encontra-se ainda aí o empresário, embora não seja proprietário fundiário como o fazendeiro e o minerador, mas que dirige e explora, como estes, uma numerosa mão de obra que trabalha para ele e sob suas ordens. (PRADO JR., 2011, p. 128).

Nesta concepção, o intérprete também nos apresenta uma chave de análise para pensar as particularidades do modelo de desenvolvimento na Amazônia, ainda hoje em curso com ressalvas à inexistência da grande propriedade, modificada com a política desenvolvimentista especialmente na década de 1970. Como nos aponta Nascimento (2009, p. 40 - grifos nossos), "o movimento diferenciado da acumulação capitalista, tanto no passado como no presente da Amazônia brasileira, tem se realizado por meio do extrativismo vegetal e mineral". Tal afirmação leva a considerarmos que a acumulação capitalista na Amazônia, diferentemente dos grandes polos centrados na atividade produtiva oriunda da industrialização, traduzse com mais ênfase na forma primária de exploração dos recursos naturais e no beneficiamento de produtos semielaborados ou commodities para exportação. De acordo com Loureiro (2002, p. 107 - grifos no original), a Amazônia sempre foi mais rentável e mais útil economicamente à metrópole e ao país do que eles o foram para a região:

A Amazônia foi no passado 'um lugar com um bom estoque de índios' para servirem de escravos, no dizer dos cronistas da época; uma fonte de lucros no período das 'drogas do sertão', enriquecendo a Metrópole; ou ainda a maior produtora e exportadora de borracha, tornandose uma das regiões mais rentáveis do mundo, numa certa fase.

Esse padrão de desenvolvimento capitalista tem como base um modelo econômico em que as atividades produtivas são destinadas ao mercado externo, sem integrar-se ao mercado local, ou seja, "uma sociedade e uma economia que se organizam para fora e vivem ao sabor das flutuações de interesses e mercados longínquos" (IANNI apud BEHRING, 2008, p. 86).

Nosso intérprete também destaca as atividades que não pertencem à "grande exploração" ou que nela têm um papel subsidiário, destinadas a amparar e tornar possível a realização da agricultura, mineração e extrativismo. Essas atividades são voltadas para o mercado interno, como a agricultura de subsistência e a pecuária (desenvolvida especialmente no sertão nordestino), e não serviriam para caracterizar o cerne da economia colonial brasileira, constituindo o que Caio Prado Jr. considera como o segmento inorgânico da economia. Neste segmento, a lógica de funcionamento não é presidida diretamente pelos fins últimos que dão sentido à colonização, 


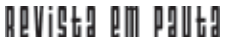

\} SETORES ORGÂNICO E INORGÂNICO NA FORMAÇÃO SOCIAL BRASILEIRA - PEREIRA, E. M.; BARROSO, M. F. \}

DOI: $10.12957 /$ REP.2016.27844

ou seja, a grande exploração ou a organização da produção para fora (LIMA, 2008).

É interessante observarmos que a caracterização feita por nosso autor entre os setores orgânico e inorgânico no processo de colonização pode revelar aspectos que compõem o desenvolvimento desigual e combinado (TROTSKY, 1977) e produzem uma característica permanente na constituição do Brasil: as desigualdades regionais. Estas, partícipes do movimento de concentração e centralização do capital, são resultantes das contradições do modo de produção capitalista, "sinal de uma redefinição da divisão regional do trabalho no conjunto do território nacional" (OLIVEIRA, 2008, p. 163).

Se, de um lado, o Norte do país, especialmente a Região Amazônica, conserva seu lugar na economia nacional a partir do extrativismo, de outro, o Nordeste brasileiro recompõe de forma particular os aspectos próprios da formação social do país, a exemplo das raízes oligárquicas e patriarcais, cumprindo o papel, no âmbito econômico, de oferta de mão de obra abundante em relação a outras regiões onde se concentram as riquezas produzidas no país. Nesse sentido, historicamente a dinâmica capitalista, sob vigência da lei da concorrência, estabelece com mais afinco as fronteiras regionais (PEREIRA, 2011).

Tal concepção se contrapõe à "teoria do dualismo econômicosocial" que, conforme lanni (1965, p. 74), concebe a "fisionomia singular do Nordeste ou da Amazônia, em face do Centro-Sul [...] como uma manifestação das dualidades que permeiam fatalmente a realidade nacional [...] e que precisam ser superadas como tais. Fala-se em 'dois brasís', atraso cultural [...] e assim por diante". Essa perspectiva é sustentada, por exemplo, em conceitos como o de "formação histórico-econômica singular", constituída por dois polos opostos - o atrasado e o moderno, o que, conforme Oliveira (2013, p. 32), "não se sustenta como singularidade", pois "esse tipo de dualidade é encontrável não apenas em quase todos os sistemas, como em quase todos os períodos". Daí a ser meramente formal a oposição entre o arcaico e o moderno. Na verdade, o que existe é uma verdadeira "simbiose [...] uma unidade de contrários, em que o chamado 'moderno' cresce e se alimenta da existência do 'atrasado'".

Em síntese, a economia do Brasil na colônia tem como características centrais, de um lado, a organização da produção e do trabalho, assim como a concentração da riqueza que dela tem origem; e, do outro, a sua orientação, voltada para o exterior, fornecedora do comércio internacional. Para Caio Prado (2011, p. 129-132) esse foi o retrato de três séculos depois do início da colonização, que trouxe uma grave e histórica consequência: a evolução cíclica da economia colonial no tempo e no espaço "em que se assiste sucessivamente a fases de prosperidade estritamente localizadas, seguidas, depois de maior ou menor lapso de tempo, mas sempre curto, do aniquilamento total". 
Tal "evolução cíclica" teria raiz na ausência de um sistema organizado da produção e distribuição de recursos para a subsistência material interna, ou seja, o Brasil subordina-se inteiramente aos interesses externos por não contar com forças próprias e existência soberana, resultando em processos de destruição da natureza, miséria da população e desigualdades regionais. Essa tendência irá se fazer presente nos períodos imperial e republicano, embora se modifiquem as condições da relação dessa subordinação com o mercado mundial.

Com as ressalvas necessárias, entre as quais aquelas postas ao seu tempo histórico, Caio Prado, ao caracterizar a economia colonial, nos convida a observar as particularidades da formação do capitalismo brasileiro e a importância de sua constituição como uma nação. Na superação do estatuto de colônia para a constituição de uma verdadeira nação, os setores inorgânicos teriam papel fundamental, conforme a nossa interpretação da obra do autor, tendo em vista que estariam voltados para a produção interna do país, ou seja, "para dentro". Mas o que de fato seria esse setor inorgânico? Ele efetivamente realizou a constituição da nação brasileira? Estamos falando do povo brasileiro? Qual a diferença entre os setores orgânico e inorgânico e sua relação com a conformação das classes sociais no país? Como podemos atualizar essa interpretação a partir do Brasil contemporâneo? É possível?

Tais questões certamente demandam um estudo mais aprofundado sobre a realidade brasileira a partir de um diálogo mais denso não apenas com o nosso intérprete, o que o presente artigo pode vir a contribuir, subsidiando passos posteriores. Assim, apresentamos, a partir de então, alguns elementos da análise feita por Prado Jr. que vão ao encontro das problematizações dispostas acima.

\section{As classes sociais e a conformação do orgânico e inorgânico na sociedade brasileira}

O debate sobre os setores orgânico e inorgânico no processo de constituição do povo brasileiro e de suas classes sociais talvez seja um dos aspectos mais originais da obra pradiana. O orgânico, representado na escravidão ou no "clã-patriarcal", seria o setor ligado à grande exploração, ao núcleo central da unidade produtiva; já o inorgânico, as populações "intermediárias", "livres" ou mesmo os "indivíduos de ocupações mais ou menos incertas e aleatórias ou sem ocupação alguma" (PRADO JR., 2011, p. 299). Nos termos do autor,

vimos estes dois aspectos da sociedade colonial: de um lado, o escravo ligado ao seu senhor, e integrados ambos nesta célula orgânica que é o 'clã' patriarcal de que aquele laço forma a textura principal; doutro, o setor imenso e inorgânico de populações desenraizadas, 


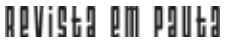

\} SETORES ORGÂNICO E INORGÂNICO NA FORMAÇÃO SOCIAL BRASILEIRA - PEREIRA, E. M.; BARROSO, M. F. \}

DOI: $10.12957 /$ REP.2016.27844

flutuando sem base em torno da sociedade colonial organizada; chegando apenas, em parcelas pequenas, a se agregar a ela, e adquirindo assim os únicos visos de organização que apresentam. (PRADO JR., 2011, p. 363).

Para Bernardo Ricupero (2007), a visão de totalidade de Caio Prado sobre a grande exploração, ao ressaltar a desarticulação entre produção, voltada para fora, e o consumo da maior parte da população, traz uma visão original da formação social brasileira na concepção do setor orgânico e do inorgânico. Para nosso intérprete, uma das grandes contradições da sociedade colonial "se encontra na estreita base econômica em que se assenta o sistema colonial, incapaz de incorporar e sustentar o crescente contingente de população que vive à sua margem, constituindo os chamados segmentos inorgânicos" (LIMA, 2008).

O papel da escravidão na constituição desses dois setores é central. No setor orgânico, a escravidão se constitui como alicerce na produção ou, nas palavras de Prado Jr. (2011, p. 364), no "fator trabalho e fator sexual". Neste último caso, o autor refere-se, especialmente, à mulher escrava, "utilizada como instrumento de satisfação das necessidades sexuais de seus senhores e dominadores", indicando a presença de relações patriarcais desde o sistema colonial escravista brasileiro. De acordo com Aguiar (2000), neste período o patriarcado estava presente em várias dimensões da vida social e incidia diretamente na divisão sexual do trabalho, na sexualidade e na reprodução.

No caso do setor inorgânico, "da população que o constitui e que vegeta à margem da vida colonial, não é senão um derivado da escravidão, ou diretamente, ou substituindo-a onde um sistema organizado de vida econômica e social não pôde constituir-se ou se manter". O setor inorgânico nos parece mais complexo pois envolve atividades econômicas voltadas para o mercado interno - a pecuária e a produção de mandioca e determinados gêneros agrícolas -, o comércio e a multidão de atividades de difícil classificação ou inclassificáveis. Além dessas, também envolve atividades voltadas à vida social, correspondendo ao "número que vai avultando com o tempo, dos desclassificados, dos inúteis e inadaptados; indivíduos de ocupações mais ou menos incertas e aleatórias ou sem ocupação alguma" (PRADO JR., 2011, p. 299-365).

Os setores fundamentais e essenciais da economia colonial brasileira [...] são aqueles que se voltam para a produção de mercadorias exportáveis, isto é, destinadas ao mercado exterior. [...] É para fornecer açúcar, ouro e diamantes e mais alguns poucos produtos primários ao comércio internacional, que se ocupou e povoou o território que constituiria o Brasil e se instalou nele uma sociedade humana. Tudo mais é acessório daquela função comercial. (PRADO JR., 1972, p. 44). 


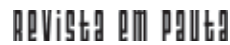

| SETORES ORGÂNICO E INORGÂNICO NA FORMAÇÃO SOCIAL BRASILEIRA - PEREIRA, E. M.; BARROSO, M. F. \} DOI: $10.12957 /$ REP.2016.27844

Para Hanna (2007, p. 81-82), a análise das classes sociais na obra Formação do Brasil contemporâneo é substituída pelas categorias do setor orgânico e inorgânico (que representam os papéis político-econômicos dos setores presentes no Brasil Colônia), pois nesta obra o autor privilegia a necessidade primeira da independência econômica do país a partir da produção e do consumo. Se, para Marx (2011), são as relações de produção que formam as classes sociais (classe em si), a análise dos setores orgânicos e inorgânicos na produção material da sociedade colonial parece-nos pertinente, pois mesmo que não elucide de forma direta as lutas entre as classes sociais evidencia que

o condicionante das relações sociais não se realizava ao nível da superestrutura. Estava nas relações primárias de estruturação da produção de gêneros para exportação, isto é, tratam-se de relações cimentadas exclusivamente pelas relações de produção entre escravo e senhor (o setor orgânico da sociedade) (HANNA, 2007, p.81-82).

Para nós, nosso intérprete, a partir da concepção desses setores, apresenta uma caracterização da organização social no período colonial em meio à divisão social do trabalho e à já embrionária superpopulação relativa, "uma população trabalhadora supérflua relativamente, isto é, que ultrapassa as necessidades médias da expansão do capital, tornando-se" excedente; porém, é a "alavanca da acumulação capitalista e [...] condição de existência" desse modo de produção (MARX, 2006, p. 733-735). Tal caracterização também aponta para a conformação das classes fundamentais e de suas heterogêneas frações no processo de industrialização no país.

Ao procurar sistematizar esses setores, Prado Jr. expõe o processo permanente na história do Brasil de intensas desigualdades sociais, produzidas por contradições do modo (particular) de desenvolvimento do capitalismo que vão se desenvolver e se complexificar posteriormente, ensejando a questão social e suas expressões. Estas são incompreensíveis sem a interface da questão agrária, étnico-racial, de gênero e regional.

Portanto, compreendemos o fenômeno da questão social - e suas raízes coloniais escravistas, ainda que latentes - como sinônimo de contradição, exploração, acumulação, antagonismos, conflitos e lutas sociais geradas no interior da sociedade capitalista brasileira, traduzindo-se, historicamente, pelo enfrentamento da servidão indígena, da expropriação do negro, mas, fundamentalmente, pelas lutas mais recentes por melhores condições de vida e de trabalho no período industrial, em que ganha expressão e legitimidade, como decorrência das lutas operárias. (SILVA, 2014, p. 42).

Na análise de Ricupero (2000), apesar da desorganização que marcaria o setor inorgânico, é para ele que Caio Prado Jr. volta suas expectativas, afinal, se a colônia estaria direcionada para fora, tal setor, por 


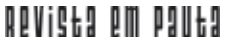

\} SETORES ORGÂNICO E INORGÂNICO NA FORMAÇÃO SOCIAL BRASILEIRA - PEREIRA, E. M.; BARROSO, M. F. \}

DOI: $10.12957 /$ REP.2016.27844

escolha ou falta dela, estaria voltado para dentro do país. Sugere, assim, que se deve partir do setor inorgânico para se constituir algo diferente da colônia: uma nação. Em outras palavras, seria a presença marcante do segmento inorgânico que faria surgir o projeto de formação de uma verdadeira nação ou "a configuração de um país e sua população voltados essencialmente para si mesmos e organizados econômica, social e politicamente, em função de suas próprias necessidades, interesses e aspirações" (PRADO JR. apud RICUPERO, 2000, p. 219).

Contraditoriamente, mesmo diante dessa importância dada ao setor inorgânico, observamos que a obra do nosso intérprete não secundariza o setor orgânico e o seu papel econômico e político na fundação da sociedade brasileira; ao contrário, para o autor, havia a disposição das classes fundamentais assentada em dois extremos:

de um lado, proprietários e empresários da colonização e negócio que consistia em produzir e fornecer gêneros primários ao comércio internacional. De outro lado, trabalhadores sem outro estatuto e perspectiva que contribuírem com sua força de trabalho para a realização do mesmo negócio (PRADO JR., 1972, p. 63).

Entretanto, a formação social do Brasil e sua inserção no modo de produção capitalista desdobrará, além disso, a existência de outros segmentos (onde também se destacam setores da administração civil, militar, eclesiástica etc.) que complexificam a existência desses "polos". Sobre isso, vejamos o seguinte:

A população rural ainda era suprida, e assim mesmo insuficientemente, com alimentos produzidos nas próprias fazendas, que dedicavam uma parcela de suas atividades à produção de gêneros alimentícios - a mandioca, o milho, o feijão. Era, contudo, uma produção marginal, a que se dava um mínimo de atenção, e que satisfazia muito mal às necessidades do pessoal empregado [...] constituíram-se à margem dessa economia de grandes explorações, umas pequenas e pobres culturas especializadas na produção de alimentos. Será este um setor subsidiário da economia colonial [...]. Em geral, a sua mão-de-obra não é constituída de escravos: é o próprio lavrador, modesto e mesquinho, que trabalha. Às vezes conta com o auxílio de um ou de outro preto, ou mais comumente de algum índio ou mestiço semi-servil. E interessante notar estas circunstâncias que retratam a pequena importância e significação do que constituiria, na economia agrária da colônia, um setor propriamente camponês, em contraste com a grande exploração, operada em larga escala na base do trabalho servil, e dedicada exclusivamente à produção de mercadorias exportáveis. Essa situação [...] terá importante papel tanto na configuração da estrutura social brasileira - é um dos principais fatores que contribui para a insignificância das categorias médias da população -, como na dinâmica da nossa evolução econômica, social e mesmo política. [...] O papel secundário a que o 
sistema econômico do país, absorvido pela grande lavoura, vota a agricultura de subsistência, dá lugar ao problema mais sério, talvez, que a população colonial deve de enfrentar, e que vem a ser a insuficiência alimentar. [...] Situação paradoxal, porque é a miséria e a fome a ombrearem com a prosperidade daqueles preços elevados. (PRADO JR., 1972, p. 46-47).

Como pensar, então, a burguesia no Brasil a partir dessa caracterização? Poderíamos considerá-la como parte do setor orgânico presente de forma embrionária desde a colonização? Antes de tudo, é fundamental lembrar que o modo de produção capitalista no país se desenvolveu por intermédio de relações híbridas. Diferentemente das ideias que conformam a interpretação pradiana sobre o Brasil Colônia, para alguns, chegamos a vivenciar um modo de produção particular e de transição no processo que representou a colonização no Brasil. Nessa direção, Gorender (1982, p. 911) afirma que o embrião da acumulação do capital no país se processou por intermédio do "escravismo colonial e tendo este como a fonte da própria acumulação". No entanto, o "agente organizador" do modo de produção capitalista não deixou de ser a burguesia, mediante a "extração do sobreproduto" através dos "assalariados livres como agentes diretos do processo de criação de valor". Porém, a formação dessa classe não demandará o desencadeamento de uma revolução burguesa no Brasil. Trata-se de uma sociedade em que a transição capitalista ocorre sem alterações profundas na estrutura agrária.

Esse traço favorecerá a formação de uma burguesia que se constitui decisivamente como classe dominante principal no século XX, cuja característica será a fusão (arranjos de cúpula) entre a velha oligarquia escravocrata e o novo empresariado, como também o caráter de dependência ao capital estrangeiro, destituída de um projeto de nação.

O padrão de acumulação voltado para fora faz com que parte do processo de realização da mais-valia produzida no Brasil dependa de mercados internacionais. Constrói-se uma dependência estrutural não somente entre a burguesia brasileira e os países centrais, mas também determina a subordinação dos países dependentes ao imperialismo. Sem projeto de nação e associada ao imperialismo, a burguesia no Brasil priorizou as mudanças 'pelo alto' operadas por arranjos políticos sem participação popular e preservando estruturas econômicas e sociais que concentraram a riqueza e condenaram nosso país à dependência. (FARIAS, 2013, p. 41).

Com isso, a consolidação da burguesia no poder deu-se mediante a associação com a "grande burguesia financeira imperialista" (IANNI, 2004), sob intensa exploração da classe trabalhadora, combinando "duas táticas calculistas [...] a do paternalismo e a da repressão policial" (GORENDER, 1982, p. 49). Ademais, a divisão social das classes é naturalizada 


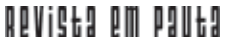

\} SETORES ORGÂNICO E INORGÂNICO NA FORMAÇÃO SOCIAL BRASILEIRA - PEREIRA, E. M.; BARROSO, M. F. \}

DOI: $10.12957 /$ REP.2016.27844

e destituída de determinação histórica ou material da exploração. Conforme Chauí (2000, p. 93-94), resulta desse processo um conjunto de práticas que ideologicamente "estruturam a sociedade sob o signo da nação una e indivisa, sobreposta como um manto protetor que recobre as divisões reais que a constituem". Nesta direção, a burguesia no Brasil se consolida (e se moderniza), conservando as marcas da sociedade colonial escravista, a partir "da estrutura hierárquica do espaço social que determina a forma de uma sociedade fortemente verticalizada", em que as relações sociais se manifestam "como relação entre um superior, que manda, e um inferior, que obedece" sob os auspícios do autoritarismo, mesmo em contextos democráticos.

Como, então, pensar as classes trabalhadoras nessa caracterização? Poderíamos considerá-las a partir da imbricação entre parte do setor orgânico (os escravos) e do setor inorgânico (os "desclassificáveis")? Desenvolver tal análise a partir do "sentido da colonização" nos possibilita confirmar a complexa heterogeneidade das classes sociais no Brasil.

Do ponto de vista étnico-racial, deve-se compreender, por exemplo, o "lugar" subalterno ocupado por negros e indígenas na sociedade brasileira, com destaque para as evidências contemporâneas do presente racismo, pauperismo, genocídio e etnocídio dessa população. Afinal, a composição étnica e a distribuição geográfica dessas etnias condicionaram as atividades econômicas da colônia - diga-se, os negros escravos - nas áreas de maior atividade econômica, nas principais áreas agrícolas - no litoral do Maranhão, extremo Nordeste, Recôncavo Baiano e Rio de Janeiro -, nas áreas mineradoras - Minas Gerais e Mato Grosso. Os brancos também estavam nesses mesmos locais, mas só permaneciam em momentos de prosperidade. Os negros permaneceram mesmo após a decadência da agricultura e mineração. Já os indígenas estavam presentes no extremo Norte Pará, Maranhão e Amazônia - e no Nordeste (PRADO JR., 2008).

Hanna (2007, p. 70), sobre a análise da obra pradiana, assevera que, para o referido autor,

Negros/as, brancos/as, índios/índias formam o mosaico ético da colonização, sendo que as duas primeiras apresentam uma complexidade étnica que não pode ser visualizada pelo colonizador branco devido a sua homogeneidade. Tais especificidades [étnico] raciais vão determinar a reação delas diante do processo histórico da colonização.

Do ponto de vista das relações de gênero (aspecto não enfatizado diretamente pelo nosso intérprete), as desigualdades (que não se confundem com diferenças) se apresentam de forma transversal às classes fundamentais ancoradas pelas relações patriarcais (já destacado anteriormente). Autores como Silvio Romero, Nísia Floresta, Oliveira Vianna, Gilberto Freyre, Joaquim Nabuco, Sérgio Buarque de Holanda e Antônio Cândido apontam o patriarcado no Brasil como uma herança do sistema escravista. Florestan 


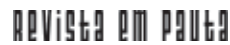

| SETORES ORGÂNICO E INORGÂNICO NA FORMAÇÃO SOCIAL BRASILEIRA - PEREIRA, E. M.; BARROSO, M. F. \} DOI: $10.12957 /$ REP.2016.27844

Fernandes, Fernando Henrique Cardoso, Otávio lanni e Heleieth Saffiotti ampliam esse eixo de interpretação, tomando a sociedade escravista do Brasil Colônia como ponto de partida histórico, classificando-a simultaneamente como escravocrata e senhorial. Para esse último grupo de autores, o escravismo não pode ser visto de forma isolada, mas como origem da acumulação capitalista (AGUIAR, 2000).

Essa herança fundamenta, na cena contemporânea, a divisão sexual do trabalho, a violência de gênero (com destaque para a violência contra as mulheres) e a ínfima participação das mulheres nos espaços de decisão e poder. Conforme aponta Cisne (2014, p. 23),

há expressões de hierarquias no interior da classe trabalhadora, advindas da própria forma de organização da sociedade. As diferenças hierárquicas que a constitui são apropriadas pelo capital na sua dinâmica de produção e reprodução de desigualdades associadas ao seu processo de acumulação.

Na tentativa de atualizar as importantes contribuições de Prado Jr., caberia uma reflexão sobre a concretização dos atributos dados tanto ao setor inorgânico, como central na constituição da nação brasileira, do "novo", quanto ao setor orgânico, formado supostamente por segmentos "centrais", "passivos" e "reprodutores" do "velho". ${ }^{3}$ Não teria sido uma caracterização pensada apenas para o "Brasil Colônia"? Tais setores, com o passar do tempo, não se metamorfosearam e se amalgamaram? Caso contrário, quais os segmentos e frações de classes formariam hoje o setor orgânico e inorgânico?

Na pretensão de uma síntese (se é possível) frente a tais questionamentos, tomamos as palavras de lanni (2004, p. 92-93) como nossa principal referência nesse momento:

O grande peso do mundo agrário na formação social capitalista brasileira, e a persistência de complexos e drásticos antagonismos no campo, tudo isso transforma o trabalhador rural em uma força básica do processo da revolução brasileira [...]. São muitos, antigos e recentes os protestos sociais do trabalhador rural: camarada, colono, morador, peão, sitiante, parceiro, arrendatário, operário, bóia-fria, seringueiro, boiadeiro, campeador e muitos outros. São muitos os confrontos assinalando a história das lutas sociais no campo, das greves aos conflitos abertos. É nessa perspectiva que se situam os acontecimentos de Canudos, Contestado, Trombas e Formoso, Bico do Papagaio, Anoni e outros [...]. Além da luta pela terra, caberia avaliar politicamente as contradições sociais desenvolvidas com a

\footnotetext{
"A contribuição do escravo preto ou índio para a formação brasileira é, além daquela energia motriz, quase nula. Não que deixasse de concorrer, e muito, para nossa 'cultura', no sentido amplo em que a antropologia emprega a expressão; mas é antes uma contribuição passiva, resultante do simples fato da presença dele e da considerável difusão do seu sangue, que uma intervenção ativa e construtora" (PRADO JR., 2008, p. 270).
} 
proletarização aberta e disfarçada no campo. É nessa perspectiva que se podem compreender as condições e possibilidades da classe operária na revolução brasileira [...]. O operário do campo e o camponês [...] podem somar-se ao operário urbano. Não apenas como aliado, mas como força revolucionária que possui reivindicações às vezes mais profundas.

Nessa ótica, poderíamos associar os povos indígenas, ribeirinhos, quilombolas camponeses - destituídos das condições básicas de sobrevivência, expropriados de suas terras, do trabalho e de suas culturas, apesar dos limites postos tanto na inserção no processo produtivo como pela agudização da crise capitalista - ao setor inorgânico, portanto, aqueles segmentos que mais representam formas de resistência ao modelo de desenvolvimento em curso no Brasil? Seria, então, o trabalhador "livre" parte do núcleo orgânico da sociedade brasileira hoje?

Na verdade, a classe trabalhadora brasileira não pode ser pensada fora da complexa, histórica e multifacetada relação constituída entre campo e cidade, ou melhor, entre o agricultor familiar, os indígenas, as populações ribeirinhas, os negros, os quilombolas e a figura do trabalhador "livre", assalariado (formal ou informalmente), proletarizado. É exatamente nessa relação, para lanni (2004), que se forja o "novo", a força revolucionária. Sobre isto, na obra Evolução política do Brasil, Caio Prado Jr. (2012) identifica algumas classes socais como atores indispensáveis à execução das transformações sociais (e à constituição da nação) e outras como entraves. Para nosso intérprete, não caberia só às classes sociais, mas também ao Estado Nacional, um papel importante no processo de modernização da sociedade brasileira (HANNA, 2007). Essa postura será alvo de diversas críticas ao pensador e à sua concepção de desenvolvimento capitalista no país, que não teremos como contemplar neste escrito.

Notamos também que o debate em torno da agricultura na colônia, de um lado, voltada à exportação (agronegócio/orgânico), de outro lado, ao consumo interno (familiar/inorgânico), pode também representar uma atualidade do pensamento pradiano. O Brasil não viveu uma reforma agrária e, ao longo da sua história, a questão agrária tem sido um importante pilar de manutenção da hegemonia capitalista. Assim, segundo Caume (2004, n.p.),

o país e o setor agropecuário brasileiro sofreram profundas transformações econômicas, sociais e políticas, mas a estrutura agrária permaneceu concentrada. Mesmo que a terra, para alguns, continue constituindo um meio de especulação, de reserva de valor, a agropecuária nacional já não é dominada pelo latifúndio, mas pelas formas empresariais de produção, patronais ou familiares. O aumento constante da produção, derivada de incrementos de produtividade propiciados por sucessivas inovações tecnológicas e pela incorporação de 'novas terras' (onde se destaca o cerrado), e a consolidação de uma agri- 
| SETORES ORGÂNICO E INORGÂNICO NA FORMAÇÃO SOCIAL BRASILEIRA - PEREIRA, E. M.; BARROSO, M. F. \} DOI: $10.12957 /$ REP.2016.27844

cultura empresarial de grande escala, constituem a 'nova face' do rural brasileiro.

Ao considerarmos indígenas, ribeirinhos, quilombolas e trabalhadores rurais como sendo "os inorgânicos", o que nos apresenta como central é a tensão que suas lutas e resistências proporcionam nas estruturas consolidadas e a visibilidade que esses segmentos dão "à outra face dessa modernização excludente e antidemocrática: o desemprego, o empobrecimento dos agricultores familiares, a concentração de renda, a violência, a criminalidade" (CAUME, 2004, n.p.).

Nas cidades, por sua vez, observamos as atuais configurações da classe trabalhadora a partir das transformações partícipes do novo ciclo de acumulação capitalista. Tais circunstâncias vêm produzindo continuamente, além do desemprego, modalidades de subemprego, precárias, trabalhadores informais, "sem-teto", intensificação da dupla jornada de trabalho das mulheres, utilização de mão de obra infantil e migrante e até mesmo condições de trabalho análogas ao trabalho escravo. Tais condições demonstram a inquestionável atualidade da obra do nosso intérprete.

Por outro lado, têm se produzido inúmeras greves ${ }^{4}$ manifestações, levantes juvenis e ocupações de prédios (públicos e privados), entre outros. Nesse sentido, é possível entender que o "povo brasileiro" não é uma composição homogênea, mas fundamentalmente heterogênea. Trata-se de classes trabalhadoras e setores populares que, sob o mesmo jugo da exploração capitalista, são estruturados por relações de opressões patriarcais e racistas, e hierarquizados de forma particular pela formação e organização social da questão agrária e urbana.

Tal condição pode nos ajudar a entender os setores apresentados por Caio Prado Jr. como uma unidade dialética, passível de constantes tensionamentos. Afinal,

os operários urbanos, os operários rurais e os camponeses [...], [as mulheres] além de empregados e funcionários, estão sendo explorados pelo capital imperialista. E isso refaz, acentua e alarga as contradições de classes, na cidade e no campo, no âmbito local, regional e nacional. (IANNI, 2004, p. 241).

Ao mesmo tempo, isso naturaliza relações autoritárias, comportamentos preconceituosos e discriminatórios, mentalidades conservadoras, que se convertem em privilégios e desigualdades das quais se favorece a exploração capitalista.

\footnotetext{
${ }^{4}$ Sobre isso, conforme dados do Departamento Intersindical de Estatística e Estudos Socioeconômicos (DIEESE, 2013), é possível constatar a tendência de aumento do número de greves desde 2008, gerando no país a marca de 873 em 2012, o que significa o maior número de greves desde 1997.
} 


\section{Considerações finais}

As reflexões empreendidas ao longo deste artigo nos permitiram apresentar algumas considerações e interpretações sobre os setores orgânico e inorgânico presentes na obra de Caio Prado Jr., bem como a relação entre esses setores e a configuração das classes sociais no Brasil. Antes, destacamos a importância de entender as particularidades da formação sóciohistórica brasileira e suas raízes.

O autor, ao caracterizar tais setores no Brasil colonial, contribui para o pensamento crítico e marxista, inovador para sua época, sobre a rea-lidade brasileira, proporcionando identificar a relação com as questões que envolvem o tema das classes fundamentais, da divisão social do trabalho, da acumulação primitiva, da embrionária superpopulação relativa e do caráter híbrido no qual esse processo se constituiu em meio à permanente e agravante desigualdade social, ensejando a questão social e suas expressões.

Não restam dúvidas sobre a relevância e a atualidade da obra pradiana em vários aspectos. Entre eles, a sua genialidade na construção de um pensamento sobre a realidade brasileira, conectada à expansão da sociabilidade capitalista e à abordagem das diversidades e desigualdades sociais e regionais, a partir das mudanças e permanências que demarcam momentos e perspectivas da história social brasileira. Entretanto, para nosso intérprete, os elementos de conservação assumem um grande relevo, secundarizando as possibilidades de rupturas históricas efetivas, o que, para nós, merece atenção no intuito de evitarmos o fatalismo na análise. Como exemplo disso, podemos sinalizar a concepção de "evolução cíclica da economia colonial" (PRADO JR., 2011), que, para a perspectiva crítico-dialética, pode parecer anular os elementos de renovação, como também os de ruptura, mesmo diante dos limites estruturais.

A história, a nosso ver, apresenta hoje mais elementos para pensar o papel de alguns segmentos e frações de classes na constituição do Brasil como nação, atravessada pela marca da dependência em meio à mundialização do capital (CHESNAIS, 1996). O ineditismo de Caio Prado é inconteste ao apontar essa relação de dependência brasileira, nomeada de "embaraço" em razão das dificuldades de "liberação da economia do seu passado colonial". Nos termos de Prado Jr. (1972, p. 84), "passado que, embora sob forma diferente e mais complexa, continua a mantê-la enquadrada num sistema em que ela [economia] figura como setor e elemento periférico e dependente" - diga-se, direcionada "para interesses estranhos, e não para a satisfação das necessidades econômicas e aspirações da grande massa da população brasileira".

Ou seja, podemos dizer que, com o passar do tempo, houve imbricações e mudanças entre e nos próprios setores da sociedade, afinal, "as classes não são algo dado em si, algo acabado, pelo contrário, são cons- 


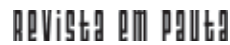

| SETORES ORGÂNICO E INORGÂNICO NA FORMAÇÃO SOCIAL BRASILEIRA - PEREIRA, E. M.; BARROSO, M. F. \} DOI: $10.12957 /$ REP.2016.27844

truções que se dão ao longo das relações sociais" (HANNA, 2007, p. 38) e, como tal, fruto de processos históricos. Daí a complexificação da sociedade brasileira e, consequentemente, dos segmentos que a compõem, não anulando a derivação, em grande medida, das relações de exploração colonial, patriarcais e escravistas (racistas) presentes na nossa formação social e que, nos termos do nosso intérprete, indicam "o sentido da colonização" (PRADO JR., 2008). Ademais, as classes sociais, em meio à diversidade, ganharam maior densidade na realidade mais recente com o advento do "capitalismo tardio" (MANDEL, 1982). Afinal, como já apontou Marx (2006), o produto da produção capitalista não é apenas mais-valia, é também capital e não apenas capital, ou seja, é também produtor de uma massa crescente de trabalhadores. Estes vão ocupar, junto aos setores burgueses, o patamar de classes fundamentais com suas particularidades sócio-históricas.

Cabe ressaltar que, antes mesmo da publicação de Formação do Brasil contemporâneo, Caio Prado, em 1933, na primeira versão do livro Evolução política do Brasil, utiliza de forma inédita no Brasil a ideia de classes sociais como conceito para analisar os movimentos sociais e políticos ao longo da história brasileira. De forma inovadora, Prado procura demonstrar os distintos interesses e os conflitos entre as classes nos diferentes contextos dessa história, com destaque para as classes populares e/ou setores inorgânicos. Eventos como a Balaiada, a Cabanada e a Revolta Praieira são citados como exemplos de resistência, ao mesmo tempo em que indicam a incipiente participação direta das classes populares nos eventos políticos do país. Isso, na nossa avaliação, reflete-se na conjuntura atual, diga-se, sob novas condições, na forma como os processos de participação social e o poder político se organizam no Brasil. A criminalização das lutas e dos movimentos sociais, bem como os golpes políticos, interditando as conquistas democráticas aos setores populares, mesmo que limitadas ao campo da emancipação política, são expressões dessa particularidade. Esta se insere em um processo de correlação de forças sociais fundamental à ofensiva à ordem hegemônica, confirmando a tese pradiana de que o sujeito da história do Brasil não são as elites isoladas, mas as classes sociais em luta (REIS, 1999).

Assim, buscamos problematizar algumas questões na tentativa de desenvolver uma leitura atualizada acerca dos setores orgânico e inorgânico. Nesse sentido, mesmo que os sujeitos que compõem o setor inorgânico sejam concebidos como aqueles que não fazem parte do núcleo orgânico da sociedade, não deixaram de participar e viabilizar o processo de reprodução ampliada do capital sob mecanismos renovados de intensificação da exploração do trabalho e das desigualdades. Tratam-se, portanto, de setores fundamentais para a reprodução da vida, das relações sociais desde a sua totalidade até as singularidades. Lembramos, porém, que "reprodução" não é necessariamente sinônimo de "passividade", ausência de conflitos, embates e disputas; ao contrário. Basta lembrar a longa e dura trajetória das lutas sociais desde o "Brasil Colônia" até o "Brasil contemporâneo". 


\section{ApVista d a panta}

\} SETORES ORGÂNICO E INORGÂNICO NA FORMAÇÃO SOCIAL BRASILEIRA - PEREIRA, E. M.; BARROSO, M. F. \}

DOI: 10.12957/REP.2016.27844

É intrigante identificar o quanto continuam vivos, ainda que amalgamados e metamorfoseados, os aspectos que constituem, para Prado Jr. (2008, p. 12), o sentido da colonização em um país que, em suma, se moderniza para se conservar. Afinal, "os problemas brasileiros de hoje, os fundamentais, pode-se dizer que já estavam definidos e postos em equação há 150 anos atrás". Isto nos diz o quanto é desafiador o predomínio do novo, da ruptura; porém, cada vez mais necessário. Somente assim será possível a constituição de uma "nação para si". Esta definitivamente não será construída pelos setores e classes dominantes que historicamente (e hoje ainda mais) prezam pela conservação. 


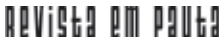

\} SETORES ORGÂNICO E INORGÂNICO NA FORMAÇÃO SOCIAL BRASILEIRA - PEREIRA, E. M.; BARROSO, M. F. \} DOI: $10.12957 / R E P .2016 .27844$

\section{Referências}

AGUIAR, N. Patriarcado, sociedade e patrimonialismo. Sociedade e Estado, Brasília, v. 15, n. 2, jun./dez. 2000. Disponível em: <http://www.scielo.br/ scielo.php?script=sci_arttext\&pid=S0102-69922000000200006>. Acesso em: 11 abr. 2016.

BEHRING, E. R. Brasil em contrarreforma: desestruturação do Estado e perda de direitos. São Paulo: Cortez, 2008.

CAUME, D. J. Reforma agrária na contemporaneidade brasileira: novos termos para um velho debate. Revista da UFG, Goiás, v. 7, n. 1, jun. 2004. Disponível em: <http://www.proec.ufg.br/revista_ufg/agro/D07_reforma. html>. Acesso em: 9 abr. 2016.

CHAUÍ, M. Brasil: mito fundador e sociedade autoritária. São Paulo: Fundação Perseu Abramo, 2000.

CHESNAIS, F. A mundialização do capital. São Paulo: Xamã, 1996.

CISNE, M. Feminismo e consciência de classe no Brasil. São Paulo: Cortez, 2014.

DIEESE. Departamento Intersindical de Estatística e Estudos Socioeconômicos. Estudos e pesquisas: balanço das greves em 2012. São Paulo: Dieese, n. 66, maio 2013.

FARIAS, J. L. P. Projeto popular para o Brasil: história e atualidade. Monografia (Graduação - Departamento de História), UECE, Fortaleza, 2013 (mimeo).

FERNANDES, F. A. Revolução burguesa no Brasil: ensaio de interpretação sociológica. São Paulo: Globo, 2006.

GONÇALVES, R. Reprimarização faz economia brasileira retroceder (Entrevista). Revista do Instituto Humanitas Unisinos On Line, ano X, n. 338, ago. 2010. Disponível em: <http://www.ihuonline.unisinos.br/index.php? option=com_content $\&$ view $=$ article $\& i d=3405 \&$ secao $=338 \&$ limitstart $=1>$. Acesso em: 17 jul. 2013.

GORENDER, J. A burguesia brasileira. São Paulo: Brasiliense, 1982.

HANNA, F. T. V. As classes sociais brasileiras em Caio Prado Júnior: papéis político-econômicos na consolidação da nação (1933-1966). Tese (Doutorado - Programa de Pós-Graduação em História), Unesp, São Paulo, 2007. Disponível em: <http://hdl.handle.net/11449/103198>. Acesso em: 15 abr. 2016.

IAMAMOTO, M. V. Serviço Social em tempo de capital fetiche: capital financeiro, trabalho e questão social. São Paulo: Cortez, 2007. 
IANNI, O. Estado e capitalismo: estrutura social e industrialização no Brasil. Rio de Janeiro: Civilização Brasileira, 1965. . Pensamento social no Brasil. São Paulo: Edusc, 2004.

LENIN, V. I. O desenvolvimento do capitalismo na Rússia. O processo de formação do mercado interno para a grande indústria. São Paulo: Abril Cultural, 1982.

LIMA, V. F. S. A. Caio Prado Júnior. Formação do Brasil contemporâneo: colônia. Revista Políticas Públicas, São Luís (MA), v. 12, n. 1, jan./jun. 2008. Disponível em: <http://www.revistapoliticaspublicas.ufma.br/site/ download.php?id_publicacao=163 >. Acesso em: 30 mar. 2016.

LOUREIRO, V. R. Amazônia: uma história de perdas e danos, um futuro a (re)construir. Revista Estudos Avançados, São Paulo (SP), v. 16, n. 45, maio/ ago. 2002. Disponível em: <http://www.scielo.br/scielo.php?script=sci _arttext\&pid=S0103-40142002000200008>. Acesso em: 24 jan. 2016.

MANDEL, E. O capitalismo tardio. São Paulo: Abril Cultural, 1982.

MARX, K. O 18 brumário de Luís Bonaparte. In: MARX, K. A revolução antes da revolução, II. São Paulo: Expressão Popular, 2011.

. O capital: crítica da economia política. Livro I. São Paulo: Civilização Brasileira, 2006.

NASCIMENTO, M. A. C. O paradoxal desenvolvimento do estado do Pará: efeitos no social. In: SCHERER, E. (Org.). Questão social na Amazônia. Manaus: Edua, 2009.

OLIVEIRA, F. Elegia para uma re(li)gião: Sudene, Nordeste. Planejamento e conflitos de classes. São Paulo: Boitempo, 2008.

. Crítica a razão dualista. São Paulo: Boitempo, 2013.

PEREIRA, E. M. Cooperação e hegemonia na dinâmica do capitalismo contemporâneo: a cooperação agrícola e organização política dos trabalhadores rurais na Lagoa do Mineiro/Ceará. Dissertação (Mestrado - Programa de Pós-Graduação em Serviço Social), UFPE, 2011 (mimeo).

POCHMANN, M. Políticas públicas e situação social na primeira década do século XXI. In: SADER, E. (Org.). 10 anos de governos pós-neoliberais no Brasil: Lula e Dilma. São Paulo: Boitempo; Rio de Janeiro: Flacso Brasil, 2013.

PRADO JR., C. História e desenvolvimento: a contribuição da historiografia para a teoria e prática do desenvolvimento brasileiro. São Paulo: Brasiliense, 1972. 2008.

. Formação do Brasil Contemporâneo: colônia.São Paulo: Brasiliense, 


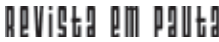

\} SETORES ORGÂNICO E INORGÂNICO NA FORMAÇÃO SOCIAL BRASILEIRA - PEREIRA, E. M.; BARROSO, M. F. \}

DOI: $10.12957 /$ REP.2016.27844

. Formação do Brasil Contemporâneo: colônia. São Paulo: Companhia das Letras, 2011.

. Evolução política do Brasil. São Paulo: Companhia das Letras, 2012.

REIS, J. C. Anos 1960: Caio Prado Jr. e "A revolução brasileira". Revista Brasileira de História, São Paulo (SP), v. 19, n. 37, set. 1999. Disponível em: <http://www.scielo.br/scielo.php?script=sci_arttext\&pid=S010201881 999000100012\&lng=en\&nrm=iso\&tlng=pt>. Acesso em: 12 jan. 2016.

RICUPERO, B. Caio Prado Jr. e a nacionalização do marxismo no Brasil. São Paulo: Departamento de Ciências Políticas da USP; Fapesp. Ed. 34, 2000.

- Caio Prado cem anos depois. Gramsci e o Brasil, São Paulo, out. 2007. Disponível em: <http://www.acessa.com/gramsci/?id=797\&page=vi sualizar>. Acesso em: 13 nov. 2014.

SILVA, I. M. F. Questão social e Serviço Social no Brasil: fundamentos socialhistóricos. Campinas: Papel Social; Cuiabá: EdUFMT, 2014.

TROTSKY, L. A história da Revolução Russa. Rio de Janeiro: Paz e Terra, 1977.

Recebido em 24 de abril de 2016.

Aprovado para publicação em 29 de agosto de 2016.

DOI: 10.12957/rep.2016.27844

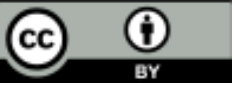

A Revista Em Pauta: Teoria Social e Realidade Contemporânea está licenciada com uma Licença Creative Commons Atribuição 4.0 Internacional. 